\title{
Exploring and Promoting Mental Health Literacy and Outcomes: Introduction to the Special Issue
}

\author{
Jessica Whitley, Suzanne Gooderham \\ University of Ottawa
}

The fields of mental health and education, both research and practice-focused, are increasingly intersecting and overlapping. On one hand there are frequently cited statistics summarizing the alarming rates of mental health disorders among Canadian children and youth (14-25\% according to the School-Based Mental Health and Substance Abuse Consortium, 2013). On the other hand there is a strong emphasis in provincial policy on student health and well-being (e.g., Government of Saskatchewan, 2016) and many classroom and board-level examples of universal approaches to strengthening social and emotional skills among students and staff (e.g., Rocky View Schools, 2016). Recognition of the inseparable nature of the domains of health, learning, and school success is slowly growing across the various levels of government.

As was evident from the many related presentations at the 2015 and 2016 conferences of the Canadian Association for Educational Psychology, researchers, teacher educators, and practitioners are invested in exploring effective ways to continue strengthening the health and well-being of Canadian children and youth and to evaluate models of intervention.

The articles in this issue are connected through the goal of exploring and promoting mental health and mental health literacy in different areas of the education system with the ultimate aim of improving outcomes for children and youth. The articles highlight and improve our understanding of a number of themes, including the importance of early identification of existing and emerging mental health difficulties; the key role that school staff, particularly teachers, play in the recognition of, and response to mental health issues; and the importance of ongoing support of students experiencing difficulties.

An important feature of this issue is that the articles present a variety of perspectives both on the understanding of mental health difficulties and on the impact these can have on learning. Of particular value is that this collection of articles provides insight by exploring the issues from diverse viewpoints (younger students, students with exceptionalities, families, and pre- and in-service teachers) and in a range of settings (mental health agencies 
and elementary and secondary schools, as well as post-secondary institutions and Bachelor of Education programs) using quantitative and qualitative methodologies.

The first two articles focus on the experiences of students and the impact of mental health on academic achievement. Stewart, Klassen, and Hamza explore the relationship between early school disruption and mental health concerns. They state that while the relationship between mental health and school disruption is well established, researchers have generally focused on measuring school disruption using measures of academic achievement. They contend that the disruptions themselves may be indicative of emerging or existing mental health issues and investigate the relationship between early school disruption and mental health independent of academic achievement among clinically referred children and youth. Stewart and colleagues assessed participants using the interRAI Child and Youth Mental Health assessment (ChYMH; Stewart, Currie, Arbeau, Leschied, \& Kerry, 2015), a promising 400-item tool that explores a child's medical, functional, psychological, social, and environmental strengths and needs. The ChYMH assessment is administered by trained clinicians and draws upon the reports of the child or youth, as well as those of caregivers, teachers, and physicians. The findings of Stewart, Klassen, and Hamza add to the growing literature base unpacking the closely intertwined constructs of behaviours key to academic success, including absenteeism, attitudes toward school, and mental health disorders. A greater understanding of these relationships can help with academic and program planning and co-ordination with mental health services.

In the second article, Piers and Duquette explore the lived experiences of postsecondary students diagnosed with learning disabilities and those of their families. Although it is clear that many students with learning disabilities struggle in school, both academically and socially, others have thrived and have gone on to successfully navigate and complete post-secondary studies (Raskind, Goldberg, Higgins, \& Herman, 2002; Reis, Neu, \& McGuire, 1997). Using a multiple case study approach the authors interviewed students and their families to gain diverse perspectives, thus adding to the scant related literature that has included sibling and parent voices. Through a lens of resiliency, they explore the factors that foster mental health and academic success among their young adult participants. In their study, Piers and Duquette draw on a methodology that is in sharp contrast to that of Stewart and her colleagues. The voices of the postsecondary students captured in the article speak eloquently and powerfully about their experiences. However, both capture multi-informant perspectives and seek to identify the complex influences surrounding student well-being and success.

With the third article in the issue, the focus shifts to the perspective of pre-service teachers with an exploration of mental health both from personal experience and from a general understanding of mental health issues. While recognizing that it is essential that teachers play a key role in supporting the mental health of students and therefore must have an understanding of mental health issues, Dodds also contends that pre-service teachers themselves may be at risk in terms of mental health. Considering the capacity of teachers to support and facilitate the health and well-being of the students in their classes is of major importance in the face of the growing responsibility being placed on teachers. Dodds adds to the emerging research in this area by examining both the personal mental health and mental health literacy of pre-service teachers through a quantitative survey. 
In a similar vein, Whitley and Gooderham continue the special issue's exploration of mental health literacy of pre-service teachers. Assessing teacher beliefs and knowledge about the inclusion of students presenting various internalizing and externalizing difficulties is an important step in better understanding perceptions and in creating more effective interventions. Whitley and Gooderham created a vignette-based measure in order to approximate realistic scenarios; pre-service teachers responded to closed and open-ended questions in ways that capture beliefs and behavioural intentions that are as close to actual practice as possible. As in the work of Dodds, findings that emerge from the Whitley and Gooderham article are important to consider in light of the myriad approaches that universities and school boards are considering in preparing pre-service teachers as well as those currently practising.

One approach to preparing pre-service teachers is described in the final article of the issue, in which Atkins and Rogers speak to the need for pre-service teachers to be better prepared to recognize mental health difficulties and to support students who might be experiencing mental health difficulties. The authors outline a series of learning objectives used in the development of an online course for pre-service teachers focused on mental health education. The article describes the delivery and evaluation of this elective course and draws heavily on the voices of the participants. The findings described in this final article of the special issue add to the minimal literature in the area and represent the next phase of research, namely designing and evaluating effective approaches to preparing teachers to support their own mental health needs as well as those of their students.

The articles in this special issue explore a few of the myriad perspectives and elements surrounding mental health issues in schools. The methodologies drawn upon by the authors reflect a need for data that is as varied as the systems in which students and teachers are embedded. It is important that research in the area draw upon the voices of students at various points in their learning journey, be they a child facing the challenge of a mental health disorder in a Grade 4 classroom, a university student finding ways to regulate emotions in the face of deadlines and social pressures, or a pre-service teacher navigating a shift from taking care of her- or himself to supporting the well-being of dozens of adolescents. It is equally important in conducting research within a field where policy plays a major role, and where dozens of interventions and programs exist, that consideration be given to assessing efficacy in robust ways that capture the complexity of student and teacher mental health literacy and well-being.

\section{References}

Government of Saskatchewan. (2016). Student wellness and wellbeing [Web page]. Regina, SK: Author. Retrieved from https://www.saskatchewan.ca/government/education-and-child-carefacility-administration/services-for-school-administrators/student-wellness-and-wellbeing

Raskind, M., Goldberg, R., Higgins, E., \& Herman, K. (2002). Teaching "life success" to students with LD: Lessons learned from a 20-year study. Intervention in School and Clinic, 37, 201208. doi:10.1177/105345120203700402

Reis, S., Neu, T., \& McGuire, J. (1997). Case studies of high-ability students with learning disabilities who have achieved. Exceptional Children, 63(4), 463-479. Retrieved from http://www.cec.sped.org 
Rocky View Schools. (2016). Social and emotional learning [Web page]. Airdrie, AB: Author. Retrieved from http://www.rockyview.ab.ca/21stC/learning/socialemotional

School-Based Mental Health and Substance Abuse Consortium. (2013). School-based mental health in Canada: A final report. Ottawa, ON: Mental Health Commission of Canada. Retrieved from: http://www.mentalhealthcommission.ca/sites/default/files/ChildYouth_School_Based_Mental _Health_Canada_Final_Report_ENG_0.pdf

Stewart, S. L., Currie, M., Arbeau, K., Leschied, A., \& Kerry, A. (2015). Assessment and planning for community and custodial services: The application of interRAI assessment in the youth justice system. In R. Corrado \& A. Leschied, P. Lussier, \& J. Whatley (Eds.), Serious and violent young offenders and youth criminal justice: A Canadian perspective (pp. 355-397). Burnaby, BC: Simon Fraser University Press.

\section{Authors' Note}

Correspondence concerning this article should be addressed to: Jessica Whitley, Faculty of Education, University of Ottawa, 145 Jean Jacques Lussier, Lamoureux Hall, Ottawa, ON, K2B5C3, Canada. Email: jwhitley@uottawa.ca 